\title{
Influence of packaging information on consumer liking of chocolate milk
}

\author{
M. K. Kim, K. Lopetcharat, and M. A. Drake ${ }^{1}$ \\ Department of Food, Bioprocessing, and Nutrition Sciences, Southeast Dairy Foods Research Center, \\ North Carolina State University, Raleigh 27695
}

\begin{abstract}
Chocolate milk varies widely in flavor, color, and viscosity, and liking is influenced by these properties. Additionally, package labels (declared fat content) and brand are some of the extrinsic factors that may influence consumer perception. The objective of this study was to evaluate the effects of packaging labels and brand name on consumer liking and purchase intent of chocolate milk. A consumer acceptance test, conjoint analysis survey, and Kano analysis were conducted. One hundred eight consumers evaluated 7 chocolate milks with and without brand or package information in a 2-d crossover design. A conjoint analysis survey and Kano analysis were conducted after the consumer acceptance test. Results were evaluated by 2 -way ANOVA and multivariate analyses. Declared fat content and brand influenced overall liking and purchase intent for chocolate milks to differing degrees. A subsequent conjoint analysis $(\mathrm{n}=250)$ revealed that fat content was a driver of choice for purchasing chocolate milk followed by sugar content and brand. Brand name was less important for purchase intent of chocolate milk than fat or sugar content. Among fat content of chocolate milk, 2 and $1 \%$ fat level were most appealing to consumers, and reduced sugar and regular sugar were equally important for purchase intent. Kano analysis confirmed that fat content (whole milk, 1 , or $2 \%$ fat chocolate milk) was an attractive attribute for consumer satisfaction, more so than brand. Organic labeling did not affect the purchase decision of chocolate milk; however, Kano results revealed that having an organic label on a package positively influenced consumer satisfaction. Findings from this study can help chocolate milk producers as well as food marketers better target their product labels with attributes that drive consumer choice of chocolate milk.
\end{abstract}

Key words: chocolate milk, flavor, consumer preference

Received November 20, 2012.

Accepted April 14, 2013.

${ }^{1}$ Corresponding author: mdrake@unity.ncsu.edu

\section{INTRODUCTION}

Flavored milk is gaining popularity among children, as well as adults, due to its special taste and its ability to meet the dietary requirements for dairy foods in the United States. In 2010, about 1.8 million t of flavored milks were produced in the United States (International Dairy Foods Association, 2010). The American Dairy Council and the American School Food Service Association revealed that offering flavored milk could be one way to increase milk consumption among children and adolescents (Anonymous, 2003; Murphy et al., 2008) as well as provide nutrients, such as essential macronutrients (Ca, Mg, P, K, Zn, and vitamins A, B12, D, and riboflavin; Murphy et al., 2008). Of the flavorings in these milks, chocolate is the most popular flavor in the United States (Thompson et al., 2004; BermudezAguirre et al., 2010). Based on that finding, Garey et al. (1990) and Yon et al. (2012) concluded that school children are more likely to drink milk if they are offered chocolate-flavored milk at school.

Despite having similar nutritional benefits as regular fluid milk, chocolate milk has been criticized for its high sugar content and higher caloric content compared with regular milk (Johnson et al., 2002; Murphy et al., 2008). In 2005, the New York City Department of Education recommended replacing whole milk with low-fat or fat-free chocolate milk to reduce fat intake (CDC, 2010), and the following year New York City implemented a ban of whole milk and reduced the availability of sweetened flavored milk in the school lunch system (Golub et al., 2011). Most recently, flavored milk was banned in the Los Angeles school system as part of a child obesity prevention program (Hoag, 2011). However, experts in the Milk Industry Foundation raised concern for limiting milk options available to school children, by highlighting the continuous decline of milk consumption and simultaneous increase of competing beverages at schools. They suggested adding sugar or calorie restrictions rather than the exclusion of lowfat flavored milk in school meal systems (CMN, 2012). Additionally, recent studies have confirmed that chocolate milk is also an appropriate postexercise recovery beverage (Spaccarotella and Andzel, 2011), and have instilled new interest in chocolate milk consumption by 
sports teams. Other opportunities may also exist for chocolate milk consumption with additional information on consumer likes and desires.

Several varieties of commercial chocolate milk are available in the market, which vary in flavor, color, and viscosity. Previous research has demonstrated that cocoa aroma or flavor, cooked or eggy, and malty flavors were the positive drivers for commercial chocolate milk (Thompson et al., 2004). Later, Thompson et al. (2007) reported ethnic differences in chocolate milk preferences. The same study found that the level of fat in chocolate milk was not a differentiating factor among children (Thompson et al., 2007).

Consumer behavior in purchasing food products in the grocery store is a complex psychological, sensory, and marketing-related process. Although the sensory perception (especially with regard to flavor) of products has been regarded as the main determinant for consumer choices, other factors, such as price, consumer attitudes, and product information, also play a role in purchase decisions (Guerrero et al., 2000; Jaeger, 2006). Among the various types of information on the product package, one of the most ubiquitous and influential pieces of information is the brand name (Guerrero, 1995). Many studies have been conducted to investigate the effects of brand name in food choice for sour cream (Jervis et al., 2012b), lager beer (Guinard et al., 2001), yogurt and yogurt-like products (Bayarri et al., 2010), and crisp snack foods (Bower and Turner, 2001). Torres-Moreno et al. (2012) evaluated the effect of the entire package information on consumer liking of dark chocolates and reported that brand had the largest effect, although Arcia et al. (2012) reported that brand along with package appearance, label, and consumer previous experience affected consumer liking of low-fat cheese. Taken as a whole, the effect of brand and other packaging information on purchase decision is product-dependent. However, to our knowledge, no study has been published to evaluate the effect of brand name and packaging attributes on purchase intentions with regard to chocolate milk. Therefore, the objective of this study was to evaluate the effects of packaging labels on consumer liking and the purchase intent of chocolate milk. A consumer acceptance test and subsequent conjoint survey and Kano questionnaire were conducted.

\section{MATERIALS AND METHODS}

\section{Experimental Overview}

Consumer acceptance testing was conducted with 7 chocolate milks evaluated with and without brand (Table 1). A conjoint analysis survey was subsequently
Table 1. Milks evaluated in consumer acceptance test

\begin{tabular}{lll}
\hline Treatment & $\begin{array}{l}\text { Brand } \\
\text { type }\end{array}$ & $\begin{array}{l}\text { Declared } \\
\text { fat content }\end{array}$ \\
\hline 1 & National & $2 \%$ milk \\
2 & National & Fat-free \\
3 & Regional & Whole milk \\
4 & Regional & $1 \%$ milk \\
5 & Organic & $2 \%$ milk \\
6 & Store & Whole milk \\
7 & Store & $1 \%$ milk \\
\hline
\end{tabular}

performed 6 mo later to confirm which attribute(s) on the package, including fat content, brand name, sugar content, and organic versus conventional, were the most influential in consumer purchase intent of chocolate milk. Along with the conjoint analysis survey, a Kano functional or dysfunctional questionnaire (Berger et al., 1993) was included to gather further information about the attributes that drive consumer satisfaction of chocolate milk.

\section{Sample Selection for Consumer Acceptance Test}

Various types of chocolate milk were selected based on market share and availability; the products included one national brand, one regional brand, one store brand, and one organic brand (Table 1). A low-fat or fat-free and a $2 \%$ or whole milk version of each brand was selected, except for the organic brand, which was available only as a $2 \%$ fat version. A total of 7 types of chocolate milk were evaluated; all of the types were purchased locally and were at a minimum of 2 wk of their pull date.

\section{Consumer Acceptance Testing}

Consumer acceptance testing was performed in compliance with the North Carolina State University (NCSU) Institutional Review Board. Consumers were recruited through e-mail listservs, internet postings on campus, and from an online consumer database of 4,000 individuals in the Raleigh, North Carolina, area maintained by the NCSU Sensory Service Center. A screening survey was created using SSI Web (Sawtooth Software Version 7.12, Sequim WA). One hundred twenty consumers were recruited, and 108 consumers participated in the consumer acceptance test. Target consumers consisted of US consumers aged 19 to 65 yr with an even distribution of each age bracket (10 yr). All participants consumed chocolate milk at least a few times per mo. A 2-d crossover design (Schantz and Pontius, 1994; Cleophas and Zwinderman, 2002) was used for presentation format (brand vs. no brand) with a 1-wk interval to avoid any carryover effects due to 
memory. A crossover design is an experimental design that minimizes the variability among subjects when evaluating several treatments (Schantz and Pontius, 1994). However, the statistical power and model may be compromised if the responses in the first period carry over into the second period (Schantz and Pontius, 1994; Cleophas and Zwinderman, 2002). No significant day effects for the presentation order $(P=0.23)$ were evident.

Chocolate milk was served at $4^{\circ} \mathrm{C}$. Prior to serving, each container of chocolate milk was screened for atypical flavor by 2 highly experienced individuals $(>1,000$ $\mathrm{h}$ of experience each). Chocolate milk $(30 \mathrm{~mL})$ was poured into 3-digit coded, 207-mL clear plastic tumblers (Waddington North America Inc., Chelmsford, MA). Compusense Five version 5.2 (Compusense, Guelph, Canada) was used for data collection. All participants were compensated with a $\$ 20$ grocery gift card on their second day of participation.

On the first day of the test, all participants were asked to answer a brief questionnaire containing 11 demographic questions that included consumption characteristics. For the chocolate milk evaluation, the participants first looked at samples and evaluated the visual appearance and color on a 9-point hedonic scale. Then, participants were instructed to taste the sample and to evaluate it for overall liking, chocolate flavor liking, sweetness liking, texture or mouthfeel liking, and aftertaste liking. Just-about-right questions were asked along with liking questions for chocolate flavor, sweetness, and texture or mouthfeel. Participants used a 9-point category scale anchored on $1=$ dislike extremely to $9=$ like extremely for the liking attributes, and a 5-point just-about-right scale anchored on $1=$ not enough, $3=$ just about right, and $5=$ too much. In the case of the branded tasting, the picture of the corresponding chocolate milk container (which showed brand name and label information including product name and milk fat content) was presented before tasting, and consumers were able to recall the picture while evaluating the corresponding sample. Purchase intent questions also were asked to consumers before and after tasting the product as well as at the picture-only stage after the unbranded sample evaluation to evaluate the changes in purchase intent with and without tasting the product. Purchase intent was scaled using a 5-point category scale anchored with $1=$ definitely would not purchase, $3=$ may or may not purchase, and $5=$ would definitely purchase. The order of presentation for the chocolate milk samples was balanced and randomized within each session, and the order of presentation for the brand-only evaluation for the unbranded sets was balanced and randomized within each session. A 3-min rest period was enforced between samples and consum- ers were instructed to rinse with spring water and take a bite of an unsalted cracker.

\section{Conjoint Analysis}

A conjoint analysis survey was conducted 6 mo after consumer acceptance testing to define more clearly the attributes that drive consumer purchase behavior of chocolate milk. An online survey was created using SSI web. Four attributes (brand name, fat content, sugar content, and organic claim) were chosen based on the availability of the products in the current market and the types of product that were used in the consumer acceptance test (Table 2). Levels (contents) of product attributes that were not available in the current market were also included to determine the extent to which consumers would assign utility to those products if they were available to them. The survey was designed as an adaptive choice-based conjoint analysis model using 1 build-your-own sequence. The build-your-own sequence was followed by 6 screening tasks with 4 product concepts per task, with the possible responses of "a possibility" or "won't work for me" for each product concept (Cunningham et al., 2010; Jervis et al., 2012b). The screening task selection was followed by 14 choice task tournament sections with a minimum of 3 concepts per choice task. Root likelihood (RLH) values were analyzed to remove any respondents that showed an RLH value of 0.25 or lower.

The survey was uploaded to an internet server, and consumers $(\mathrm{n}=250)$ were recruited through e-mail listservs, internet postings on campus, and from an online consumer database of 4,000 individuals in the Raleigh, North Carolina, area maintained by the NCSU Sensory Service Center. After demographic questions, consumers answered a series of trade-off scenarios containing the predefined attributes and levels presented in Table 2. Respondents then answered a series of Kano-related

Table 2. Attributes and levels for conjoint and Kano analysis

\begin{tabular}{ll}
\hline Attribute & Level \\
\hline Brand name & Nesquik (national brand) \\
& PET (regional brand) \\
& Food Lion My Essentials (store brand) \\
& Organic Valley (organic brand) \\
& Darigold (unfamiliar brand) \\
& Whole milk \\
& $2 \%$ fat milk \\
Fat content & Fofat milk \\
& Regular sugar \\
& Reduced sugar \\
Sugar content & Sugar free \\
& Organic \\
Organic claim & Conventional \\
&
\end{tabular}


questions (described in the Kano Analysis section of this paper). Once the target number of participants completed the survey $(\mathrm{n}=250)$, utility scores were extracted and rescaled using a zero-centered difference method (Orme, 2006; Jervis et al., 2012a,b). Respondents who completed the entire conjoint analysis and Kano survey were entered into a drawing to receive one of seven $\$ 20$ gift cards to a local shopping store.

\section{Kano Analysis}

A carefully designed Kano-related questionnaire was given to the participants after the conjoint survey to determine the ways the attributes of chocolate milk affected customer satisfaction or dissatisfaction. The satisfaction questions were worded: "If you have the following choices for chocolate milk, how would you feel? As an example, your chocolate milk is made by "brand X."' The dissatisfaction question was worded: "If you have the following choices for chocolate milk, how would you feel? As an example, your chocolate milk is not made by "brand X."' The attribute levels were presented in a balanced and randomized order within a satisfaction and dissatisfaction questionnaire series (Berger et al., 1993). The answer choices for the satisfaction or dissatisfaction questions were like, must have, do not care, can live with it, and dislike (Xu et al., 2009).

\section{Statistical Analysis}

Data analysis was performed using XLSTAT (Version 2010. 5.02, Addinsoft, Paris, France). Two-way ANOVA was conducted using a general linear model. The fixed effects were brand name (branded vs. unbranded), treatment (7 types of chocolate milk), and their interactions. Day effects also were measured as random effects; however, no day effect was observed between the $2 \mathrm{~d}$ of testing $(P=0.23)$. For the consumer tests, ANOVA followed by Tukey's honestly significant difference were used for all liking scores. Purchase intent was evaluated using Kruskal-Wallis with Dunn's post hoc test. The demographic and behavior questions were analyzed for frequency of choice. Individual utility scores were extracted by hierarchical Bayesian estimation and rescaled using a zero-centered difference method (Orme, 2006; Childs and Drake, 2009). Cluster analysis was conducted using $\mathrm{K}$ means. Clusters were validated using discriminant analysis. Principal component analysis of clusters was performed on individual utility scores. All statistical analyses were carried out at a $95 \%$ significance level. Kano index and satisfaction or dissatisfaction coefficients were calculated by preparing a contingency table of consumer responses to each satisfaction and dissatisfaction question (Kano et al., 1984; Xu et al., 2009).

\section{RESULTS AND DISCUSSION}

\section{Consumer Acceptance}

Consumers' primary choice of fat content in chocolate milk varied; $29 \%$ of participants chose whole milk chocolate milk, $45 \%$ of participants drank low- or reduced-fat chocolate milk, and $27 \%$ participants chose fat-free chocolate milk. When asked about the factors that affected their purchase intent of chocolate milk, flavor was the most influential factor on purchase intent (90\%), followed by price, brand name, and nutrition. Consumers selected their most frequently purchased brand or brands (up to 2) and Nesquik (71\%), PET (44\%), Organic Valley (24\%), and store brand (57\%) were the most frequently noted.

No differences were noted in appearance liking (Table 3). Thompson et al. (2007) demonstrated that the color of chocolate milk was less influential than chocolate flavor and sweetness. A 2-way ANOVA was conducted to determine the effect of brand or package label on overall acceptance of chocolate milks. A significant treatment and brand or package label interaction for overall liking was observed $(P<0.001$; Table 3$)$. Chocolate milks 3 and 6 were made with whole milk (regional and store brand, respectively; Table 1). These 2 milks received the highest liking scores when branded or labeled, and the absence of branding and labeling decreased overall liking scores for the regional brand but not for the store brand (Table 3). Chocolate milks 1, 2, 4, and 5 did not receive high liking scores when branded or labeled (liking score $=\leq 5.5$ ), but liking scores for 2 of these milks (milks 2 and 4) increased when evaluated under blind conditions $(P<0.05$; Table 3$)$. These 4 chocolate milks were made with fat-free milk (milk 2), $1 \%$ milk (milk 4), and $2 \%$ milk (milks 1 and 5 ). Brewer et al. (1999) revealed that consumer preferences for $2 \%$ or whole-fat milk were higher than $1 \%$ or lower fat milk, and that liking scores increased with increasing fat content. Whole milk chocolate milk was generally preferred regardless of brand information or chocolate milk formulation in the current study (overall liking was 6.8 vs. 5.6 across all milks evaluated; $P<0.05$ ).

Interestingly, chocolate milks 6 and 7 were distinct in overall liking when tasted with brand and label (6.9 vs. 5.9) but were not when tasted under blind conditions (6.6 vs. 6.4) (Table 3). These chocolate milks were the same brand of whole milk and $1 \%$ chocolate milk, respectively, with fat content being the only difference. A similar effect was observed for the regional brand (milks 3 and 4 ) in regard to differences in liking 
Table 3. Consumer attribute means for chocolate milk ${ }^{1}$

\begin{tabular}{|c|c|c|c|c|c|}
\hline Treatment $^{2}$ & $\begin{array}{l}\text { Appearance } \\
\text { liking }\end{array}$ & $\begin{array}{l}\text { Overall } \\
\text { liking }\end{array}$ & $\begin{array}{l}\text { Chocolate } \\
\text { flavor liking }\end{array}$ & $\begin{array}{l}\text { Sweet taste } \\
\text { liking }\end{array}$ & $\begin{array}{l}\text { Mouthfeel or } \\
\text { thickness liking }\end{array}$ \\
\hline $1-B$ & $6.6^{\mathrm{a}}$ & $5.5^{\operatorname{defg}}$ & $5.5^{\mathrm{bcd}}$ & $5.1^{\mathrm{def}}$ & $6.0^{\text {abcde }}$ \\
\hline $2-B$ & $5.8^{\mathrm{a}}$ & $4.7^{\mathrm{g}}$ & $4.7^{\mathrm{d}}$ & $4.3^{\mathrm{f}}$ & $5.2^{\mathrm{e}}$ \\
\hline $3-B$ & $7.2^{\mathrm{a}}$ & $7.1^{\mathrm{a}}$ & $7.1^{\mathrm{a}}$ & $7.0^{\mathrm{a}}$ & $6.9^{\mathrm{a}}$ \\
\hline $4-\mathrm{B}$ & $5.8^{\mathrm{a}}$ & $4.9^{\mathrm{fg}}$ & $4.6^{\mathrm{d}}$ & $5.0^{\mathrm{def}}$ & $5.2^{\mathrm{e}}$ \\
\hline $5-B$ & $7.1^{\mathrm{a}}$ & $5.3^{\mathrm{efg}}$ & $5.3^{\mathrm{bcd}}$ & $5.2^{\text {cdef }}$ & $5.7^{\text {cde }}$ \\
\hline $6-\mathrm{B}$ & $6.9^{\mathrm{a}}$ & $6.9^{\mathrm{ab}}$ & $7.0^{\mathrm{a}}$ & $6.7^{\mathrm{ab}}$ & $6.7^{\mathrm{ab}}$ \\
\hline $7-\mathrm{B}$ & $6.9^{\mathrm{a}}$ & $5.9^{\text {cde }}$ & $5.9^{\mathrm{bc}}$ & $5.8^{\text {bcde }}$ & $6.1^{\text {abcd }}$ \\
\hline $1-\mathrm{NB}$ & $6.3^{\mathrm{a}}$ & $6.1^{\mathrm{bcd}}$ & $5.2^{\mathrm{cd}}$ & $4.9^{\mathrm{ef}}$ & $5.7^{\text {cde }}$ \\
\hline $2-\mathrm{NB}$ & $8.0^{\mathrm{a}}$ & $5.6^{\text {def }}$ & $5.0^{\mathrm{cd}}$ & $4.0^{\mathrm{f}}$ & $6.0^{\text {abcde }}$ \\
\hline $3-\mathrm{NB}$ & $5.9^{\mathrm{a}}$ & $6.4^{\text {bcd }}$ & $5.9^{\mathrm{bc}}$ & $5.9^{\text {bcd }}$ & $6.4^{\mathrm{abc}}$ \\
\hline $4-\mathrm{NB}$ & $6.1^{\mathrm{a}}$ & $6.0^{\text {cde }}$ & $5.1^{\mathrm{cd}}$ & $5.2^{\text {cdef }}$ & $5.6^{\text {cde }}$ \\
\hline $5-\mathrm{NB}$ & $6.5^{\mathrm{a}}$ & $5.9^{\text {cde }}$ & $5.1^{\mathrm{cd}}$ & $5.0^{\text {def }}$ & $5.7^{\text {cde }}$ \\
\hline $6-\mathrm{NB}$ & $6.8^{\mathrm{a}}$ & $6.6^{\mathrm{bc}}$ & $6.3^{\mathrm{ab}}$ & $6.1^{\mathrm{abc}}$ & $6.4^{\mathrm{abc}}$ \\
\hline $7-\mathrm{NB}$ & $6.9^{\mathrm{a}}$ & $6.4^{\mathrm{bcd}}$ & $5.4^{\mathrm{bcd}}$ & $5.3^{\text {cde }}$ & $5.9^{\mathrm{abcd}}$ \\
\hline
\end{tabular}

${ }^{\mathrm{a}-\mathrm{g}}$ Means in a column followed by different letters represent significant differences $(P<0.05)$.

${ }^{1}$ Liking attributes were scored on a 9 -point hedonic scale in which $1=$ dislike extremely and $9=$ like extremely ( $\mathrm{n}=108$ consumers).

${ }^{2} \mathrm{~B}=$ branded with package information; $\mathrm{NB}=$ no brand or package information.

when branded but not in the absence of the brand. The overall liking scores for these 2 milks suggest that the presence of the whole milk or $1 \%$ label played a large role in consumer perception for the store and regional brand, whereas this effect was not observed for the national brand pair (milks 1 and 2). Instead, liking scores increased for both the $2 \%$ milk and fat-free versions of the national brand when tasted in the absence of brand or label (Table 3). These results demonstrate that brand and fat content influenced consumer liking to varying degrees. Brand and declared fat content are extrinsic factors that can convey a sensory expectation to consumers depending on their previous experience (Cardello, 2007). When these attributes are present (tasting in presence of brand and label), they can positively or negatively influence liking or purchase intent to varying degrees.

Chocolate flavor and overall liking were highly correlated $(P<0.05 ; \mathrm{r}=0.86)$, and thickness or viscosity and sweet taste liking and overall liking were highly correlated $(P<0.05 ; \mathrm{r}=0.87$ and 0.80 , respectively), which is consistent with previous studies (Thompson et al., 2004). Besides overall acceptance of chocolate milks, a significant treatment and brand or package label interaction was observed for flavor liking and sweet taste liking of chocolate milk $(P<0.05$; Table 3$)$. Brand and package label positively influenced chocolate flavor liking as well as sweetness liking of chocolate milk 3, the regional brand full-fat milk. Other milks were not influenced by brand or packaging label for chocolate flavor liking and sweetness liking $(P>0.05$; Table 3$)$. No treatment and brand or package label interaction was observed for appearance and texture or mouthfeel liking $(P>0.05)$.
Previous studies reported that national brands were viewed as superior to store brands in terms of taste, appearance, labeling, and variety of choice of 5 different products, such as cheese, chips, dip, cookies, and jelly (Richardson et al., 1994). Interestingly, the current study did not find an overall positive effect of national brand or brand in general on overall liking. Rather, the influence of brand or package with fat content were variable for the overall liking scores of chocolate milks. Branding had no consistent significant effect on overall liking for the brand pairs for which we had different fat contents and no effect on the organic brand (Table 3 ). This result may confirm the general lack of brand identity and awareness, or more specifically a lack of a sensory signature for a brand(s). Fluid milks traditionally have not had a strong brand presence and instead have been sold as commodities. It is important to note that commercially available products limited the fat contents that were compared within each brand. Fat content was not the same within each brand pair; thus, we cannot absolutely conclude that observations were due solely to brand.

Brand influence on consumer purchase intent was more consistent than overall liking scores (Figure 1). The purchase intent of whole chocolate milk (milks 3 and 6$)$ increased $(P<0.05)$ following blind tasting conditions (Figure 1), suggesting that, though consumers prefer whole milk chocolate milk, they are not as likely to purchase it when they know it is whole milk, likely for perceived health reasons. The purchase intent of the national brand milks was higher when brand or package was evident with or without tasting, consistent with a national brand identity. The effect of brand or package on the purchase intent of the regional brand 


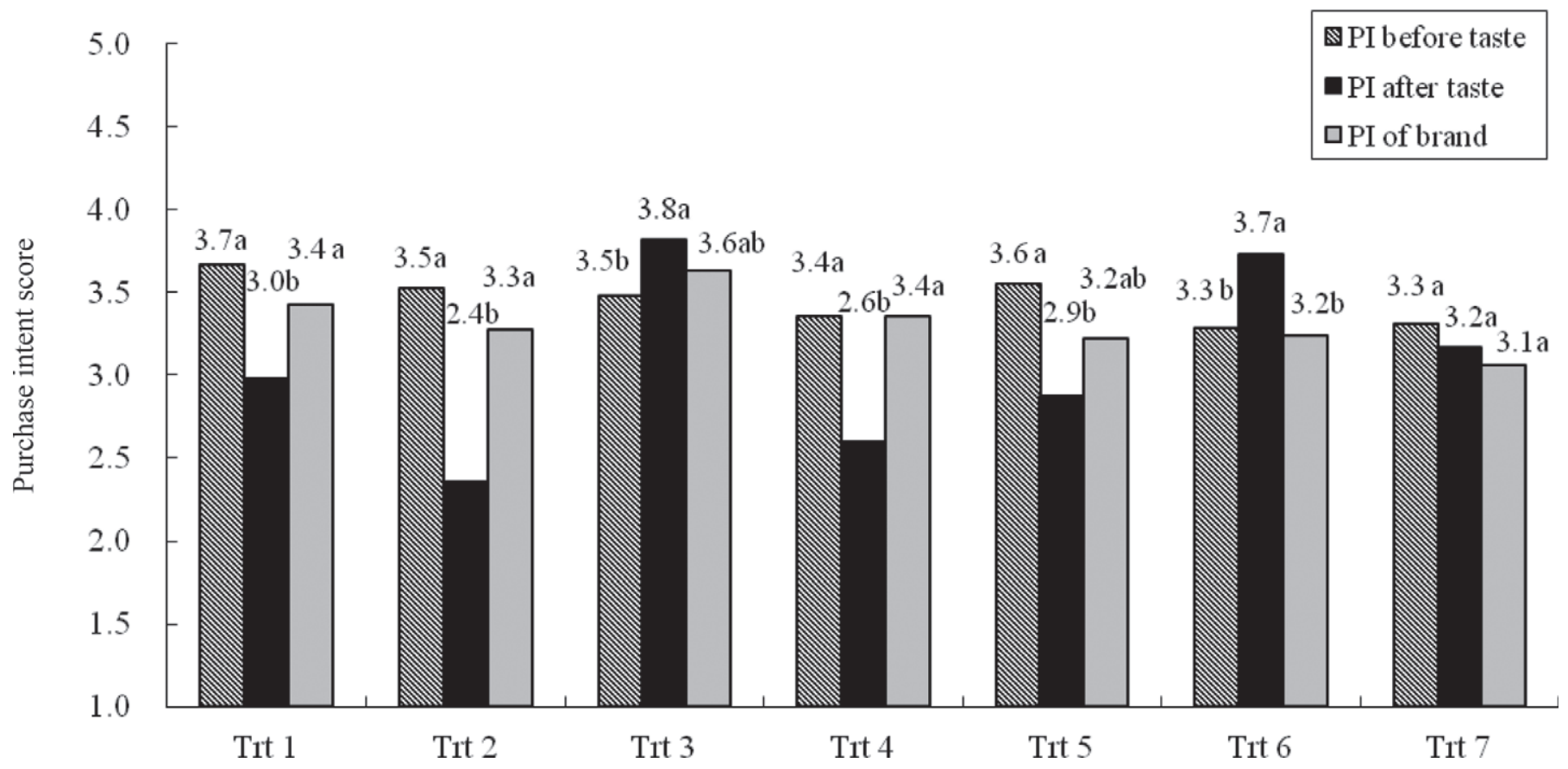

Figure 1. Effect of brand or package label on purchase intent (PI) of chocolate milk. Numbers on top of the bars represent the means of the purchase intent scores for each treatment (Trt) from 108 consumers. Letters (a,b) next to the number represent the significant difference between the unbranded (before) and branded (after) evaluation within treatments.

(milks 3 and 4) and the store brand (milks 6 and 7 ) were variable, consistent with lack of brand identity or a greater influence of fat content declaration or other sensory characteristics.

Torres-Moreno et al. (2012) showed that expected purchase intent of dark chocolates was mainly affected by the chocolate brand; the proportion of consumers who would probably or definitely purchase the sample was significantly higher for premium brand samples than for the store brand samples when evaluating just packaging of dark chocolate products. In the current study, the regional brand may have been perceived as a more premium brand than the store brand in this study; however, the same brand with different fat content (milks 3 and 4; milks 6 and 7) showed different trends (Figure 1). Therefore, the factors influencing purchase intent of chocolate milk were not solely dependent on brand, but also dependent on fat content.

The organic brand chocolate milk (milk 5) did not show any difference in overall liking scores between the branded and nonbranded taste scenarios (Table 3). However, the purchase intent decreased when consumers tasted the product blind compared with when tasted in the presence of the brand (Figure 1). These differences could be due to the appeal of the organic brand. It is important to note that only 1 organic brand was evaluated, thus results may not represent all organic brands. The overall liking and purchase intent of chocolate milks were affected by fat content as well as brand information.

\section{Conjoint Analysis}

From consumer acceptance testing, overall liking was influenced more systematically by fat content information than the influences of brand, and purchase intent was affected more by brand information than fat content. This phenomenon likely represents the 2 different scenarios in the consumption cycle: overall liking with actual tasting reflects more on repurchase after tasting products and the purchase intent reflects more on the first purchase (i.e., point-of-purchase, with or without actual tasting). To confirm the effect of brand or label information on consumer purchase intent (e.g., to separate intrinsic and extrinsic sensory cues), a conjoint study was conducted.

A total of 250 respondents completed the survey. No respondents had RLH values 0.333 or below, thus no responses were removed from the data analysis. A utility score explains the attractiveness of each attribute or level used in the conjoint analysis; therefore, higher utility scores indicate more appealing attributes. Negative utility values do not necessarily indicate an attribute is unappealing or a nondriver, but less appealing than positive utility values (Orme, 2006). Utility values cannot be compared between attributes; therefore, 
utility values within 1 attribute were compared in this study (Figure 2). Zero-centered utility scores for consumer responses $(\mathrm{n}=250)$ show that the regional brand (PET; Table 2) had the highest utility as a brand for purchasing chocolate milk along with the national brand (Nesquik). The national brand was not distinct $(P>0.05)$ in utility score from the store brand (Food Lion), and these were followed by the organic brand (Organic Valley) and an unfamiliar brand (Darigold). The unfamiliar brand did not have a market share in North Carolina, and this brand was added to determine how an unknown brand performed in comparison to known brands. Hoyer and Brown (1990) reported that brand awareness had a considerable effect on consumer choice. The unfamiliar brand received the lowest utility score among the brand attributes, which confirms the findings from Hoyer and Brown (1990). Varela et al. (2010) also showed a large effect on consumer liking scores for well-recognized brands of orange-flavored powdered drinks. In this study, a regional brand as well as a national brand received the highest utility scores among the brand attribute (Figure 2). Additionally, the national brand was not higher in utility than the store brand. Guerrero et al. (2000) investigated consumer attitudes toward store brands and found that women showed a more positive attitude toward a store brand than men (Guerrero et al., 2000). Seventy-six percent of the participants in the conjoint analysis survey were women. Olsen et al. (2011) also revealed that the consumers with a positive attitude toward private label or store brand were more likely to choose private labels instead of national brand (Olsen et al., 2011). The participant demographic may have influenced this result. The high score for the regional brand in the current study may represent a value trade-off for consumers in that the regional brand represents a familiar established brand identity but also conveys quality and value.

In terms of the fat content of chocolate milk, 2 and $1 \%$ milk received the highest utility values, followed by fat-free milk and whole milk (Figure 2). Forty percent of consumers primarily chose $2 \%$ fat chocolate milk and $24 \%$ primarily chose whole milk (total population $\mathrm{n}=$ 250; Table 4). The label $2 \%$ fat milk is appealing to consumers; studies with Cheddar cheese (Childs and Drake, 2009) and latte-style beverages (Jervis et al., 2012a) have demonstrated its appeal. A previous study

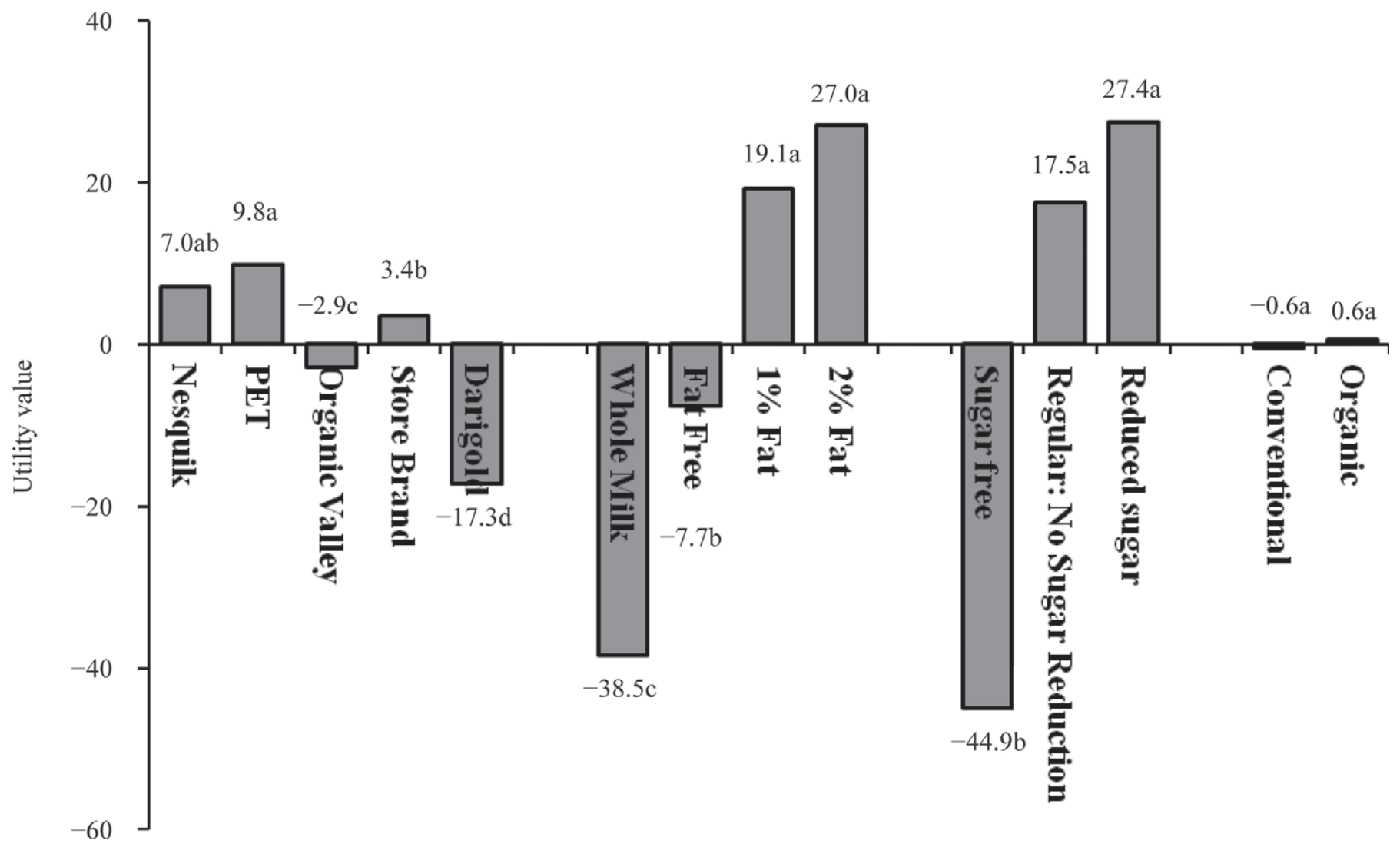

Figure 2. Zero-centered utility values for attributes and levels. Letters $(\mathrm{a}-\mathrm{d})$ indicate significant differences $(P<0.05)$ within each attribute for the total population $(\mathrm{n}=250)$. Nesquik $=$ national brand; PET $=$ regional brand; Organic Valley $=$ organic brand; Food Lion $=$ store brand; Darigold $=$ unfamiliar brand (Table 2). 
(Kim et al., 2012) also revealed that consumers preferred to see a reduced claim over a free claim for unhealthy nutrients such as fat, sodium, and sugar. As such, the conjoint analysis results from the current study are in agreement with previous studies except for the utility score of whole milk chocolate milk. Whole milk chocolate milk received the lowest utility score by conjoint analysis, whereas $24 \%$ of participants chose whole milk chocolate milk as their primary choice of chocolate milk. From consumer acceptance scores, whole milk chocolate milks (milks 3 and 6; Table 3) were also highly accepted compared with lower fat chocolate milk. Jaeger (2006) concluded that consumers typically trade several sensory and nonsensory factors when making every day food choices. Childs and Drake (2009) reported that the consumers still do not want to sacrifice flavor while seeking lower fat alternatives. The current study may be a good example of consumer behavior discrepancy, where consumers are conscious about purchase of lower fat products, but actually purchase higher fat products.

Among sugar levels of chocolate milk, a reduced sugar option was at parity with regular sugar (no sugar reduction) in chocolate milk $(P>0.05)$, but a sugarfree label was less appealing $(P<0.05$; Figure 2$)$. From the current study as well as previous studies (Thompson et al., 2004, 2007), the sweetness of chocolate milk is one of the drivers of liking, therefore consumers may not find sugar-free chocolate milk as appealing as milk with sugar. Sixty percent of the conjoint analysis participants responded that they were moderately or more interested in reduced-sugar chocolate milk (Table 4). No difference in utility scores was observed between conventional and organic labels $(P>0.05$; Figure 2$)$. Shepherd et al. (2005) showed a discrepancy between attitudes and behavior for organic products. People felt positively about organic foods but often did not purchase them. Kiesel and Villas-Boas (2007) demonstrated that the USDA organic seal on the food label increased the probability of purchasing organic milk. However, an organic label does not seem to provide more appeal than conventional chocolate milk.

Another measure that can be generated by conjoint analysis is relative importance, which indicates how important each attribute is to the whole product (Orme, 2006). Figure 3 presents the attribute importance (\%) scores for the total population and 3 identified clusters. Among the 4 attributes (fat, brand name, sugar, and organic), the attribute that was the most important in the purchase intent of chocolate milk was fat content, followed by sugar content, brand name, and organic label for the total population $(\mathrm{n}=250)$. This finding clarified the uncertainty surrounding the branding or packaging effects in the acceptance test (milks 3 and 6). Milks 2 and 4 decreased in overall liking and purchase intent after the participants knew the brand name of the chocolate milk. Based on the consumer acceptance test results alone, it was not clear if these effects were due solely to fat content or to the brand name of the chocolate milk. However, conjoint analysis of the total consumers evaluated $(\mathrm{n}=250)$ confirmed that fat content information drove the purchase intent of chocolate milk, and that the brand name was less appealing to consumers than fat content.

Segmentation of the respondents was conducted based on utility score responses, and 3 distinct clusters were identified (Figure 3 and Tables 4 and 5). Clusters 1 and 2 were similar: fat was their driver of choice (Figure 3). Cluster 1 consumers $(\mathrm{n}=47)$ responded that fat was the driver of choice, followed by brand and sugar, and organic claim had the lowest contribution to purchase of chocolate milk. Among fat levels, $2 \%$ fat chocolate milk and whole milk had the highest utilities, and fat-free had the lowest utility score (Table 5). National and regional brands showed the highest utility scores, followed by store brand. Cluster 1 members gave reduced sugar a high utility for sugar claim of chocolate milk (Table 5). Cluster 1 consisted of $79 \%$ females, $58 \%$ of cluster 1 consumers were between 25 to 44 -yr-old, and $53 \%$ of cluster 1 consumers responded that brand was one of the factors influencing purchase of chocolate milk (Table 4). Cluster 2 respondents $(\mathrm{n}=110)$ indicated that fat content was their driver of choice (48\%), followed by sugar (27\%), brand (14\%), and organic labeling (11\%; Figure 3). One percent chocolate milk or fat-free chocolate milk had the highest utility values for cluster 2 consumers, which differed from the results for clusters 1 and 3 (Table 5).

Brand name was not a differentiating attribute for cluster 2 participants. The reduced sugar option received the highest utility score for the sugar attribute, and an organic option received a higher utility value than a conventional label for cluster 2 consumers (Table 5). The main difference between cluster 1 and cluster 2 consumers was how consumers perceived brand as an important driver of choice (Figure 3). Cluster 1 consumers perceived brand as equally important as sugar content, whereas cluster 2 members chose sugar as more important attribute than brand name for chocolate milk. Fat was the leading driver of choice for both clusters. It is important to note that whole milk and $2 \%$ fat milk received high utility scores from cluster 1 respondents, but fat-free and $1 \%$ fat milk received high utility scores from cluster 2 respondents (Table 5). The respondents in cluster 2 had relatively large families; $11 \%$ lived with 5 or more people in the household, which was a higher percentage than for the other clusters. Sixty-two percent of the respondents in cluster 2 responded that their eating habits were 
Table 4. Consumer consumption characteristics and demographics of conjoint analysis participants

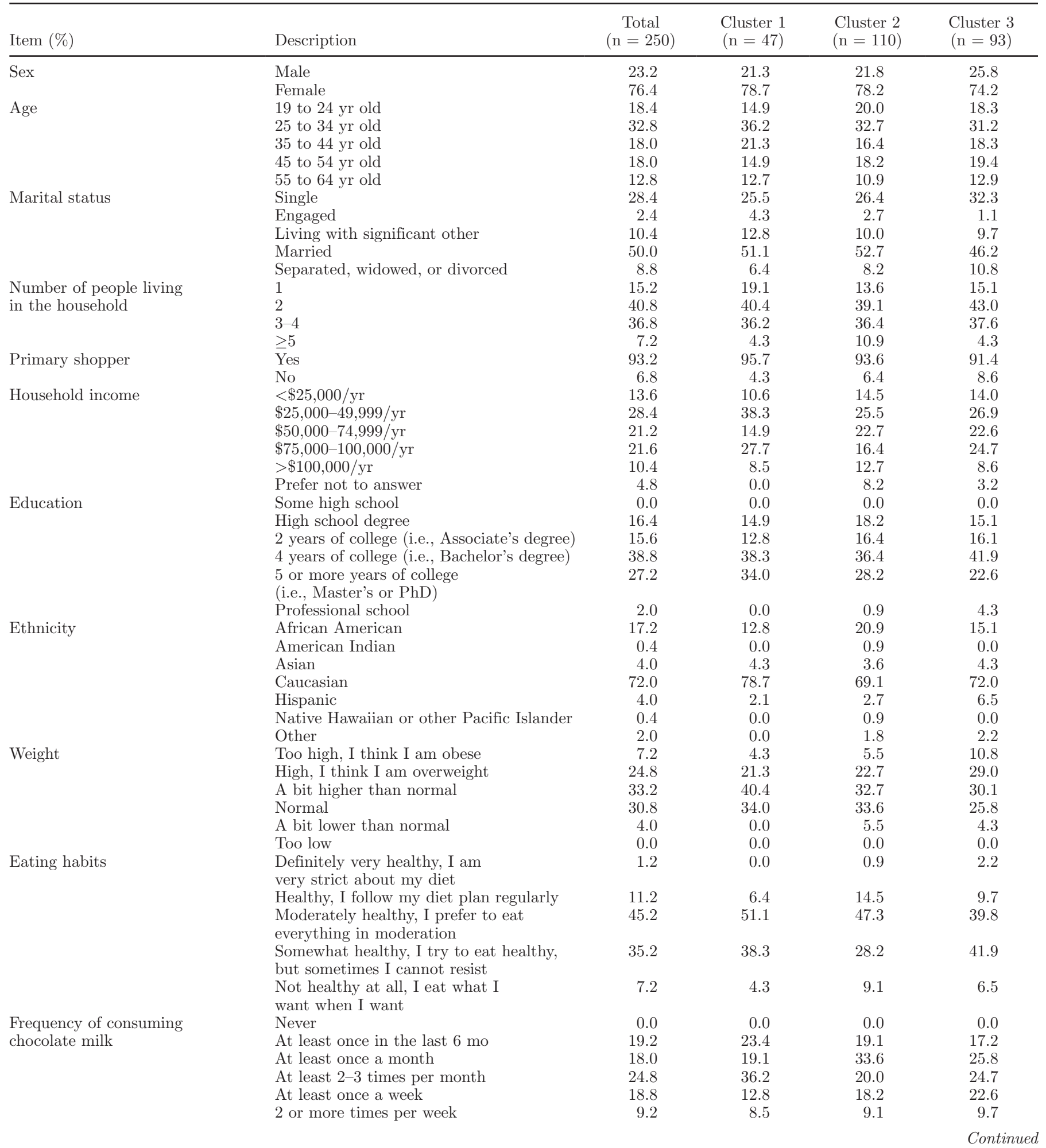


Table 4 (Continued). Consumer consumption characteristics and demographics of conjoint analysis participants

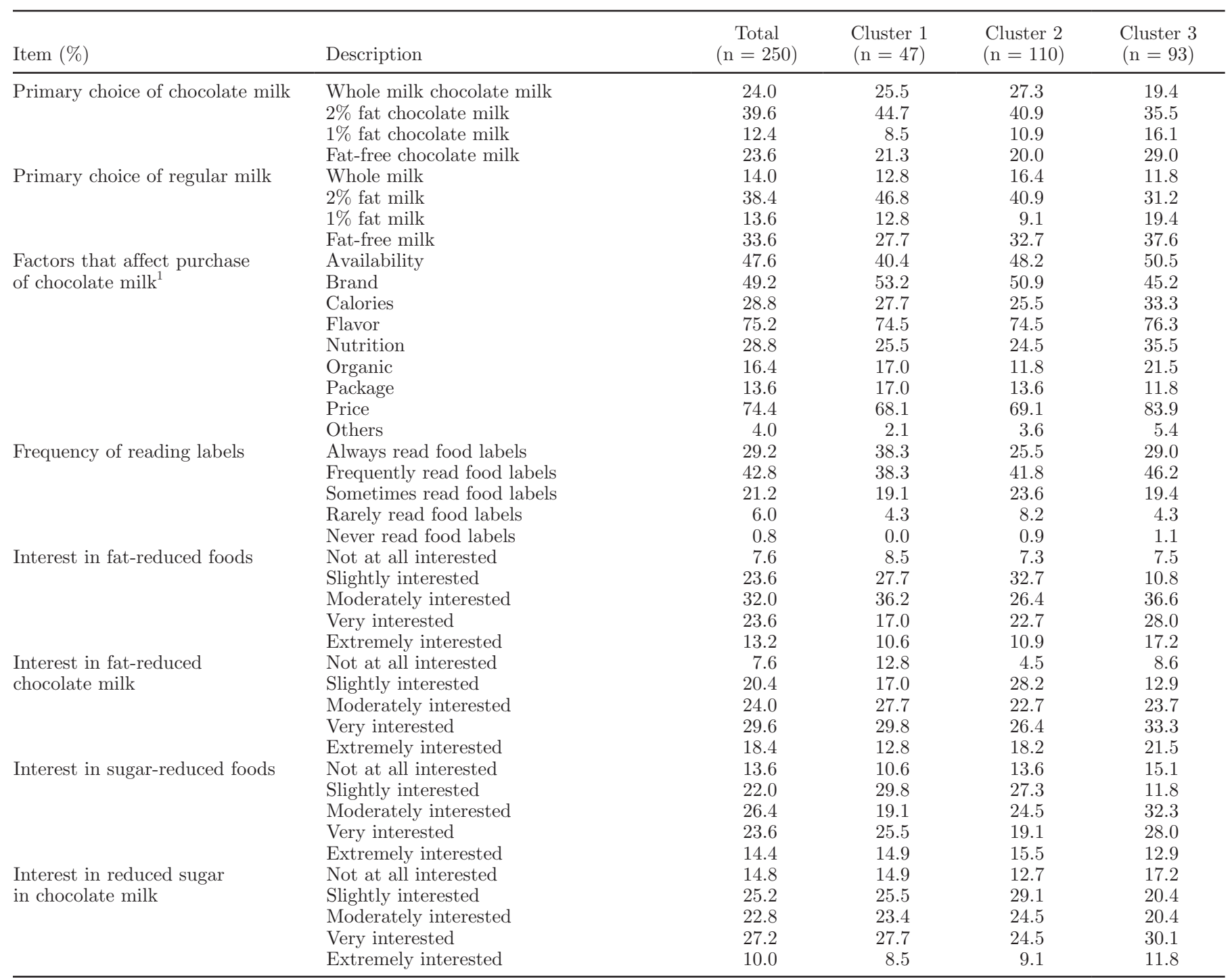

${ }^{1}$ The "Factors that affect purchase of chocolate milk" question was a check-all-that-apply-type question. Therefore, the total percentage is greater than $100 \%$.

healthy (Table 4). They did not necessarily read labels often, nor were they interested in reduced fat or sugar in food. However, the conjoint analysis revealed that cluster 2 respondents were more health conscious than the respondents for the other clusters, as fat and sugar received higher importance scores and fat-free or $1 \%$ fat in fat attribute, and reduced sugar in sugar attribute were identified as the drivers of choice for cluster 2 participants.

Cluster $3(\mathrm{n}=93)$ respondents were different from consumers in clusters 1 and 2 (Tables 4 and 5; Figure $3)$. The drivers of choice in choosing chocolate milk for cluster 3 consumers was sugar (the highest), followed by fat content. When looking at zero-centered utility values for attributes and levels in cluster 3, Darigold (an unfamiliar brand in NC) had the lowest utility value of all the brands (Table 5); however, brand name was not a differentiating attribute for the cluster 3 participants (Figure 3). Chocolate milk with $2 \%$ fat had the highest utility value, followed by whole milk, $1 \%$ fat, and fat-free chocolate milk. Thirty-five percent of consumers in cluster 3 chose $2 \%$ fat chocolate milk as their primary choice followed by fat-free milk. Regular chocolate milk with sugar (i.e., nonreduced sugar) had the highest utility value, followed by reduced-sugar and sugar-free chocolate milk. Interestingly, cluster 3 was the only group to have a higher utility score for the regular sugar option for chocolate milk. From the demographics of cluster 3 (Table 4 ), $70 \%$ of respondents in this group reported their weight as higher than normal, 
Table 5. Zero-centered utility values for attributes and levels for each segment from the conjoint analysis

\begin{tabular}{lccc}
\hline Item & $\begin{array}{c}\text { Cluster } 1 \\
(\mathrm{n}=47)\end{array}$ & $\begin{array}{c}\text { Cluster } 2 \\
(\mathrm{n}=110)\end{array}$ & $\begin{array}{c}\text { Cluster 3 } \\
(\mathrm{n}=93)\end{array}$ \\
\hline Nesquik & $35.4^{\mathrm{a}}$ & $1.58^{\mathrm{a}}$ & $-0.99^{\mathrm{a}}$ \\
PET & $21.0^{\mathrm{a}}$ & $6.36^{\mathrm{a}}$ & $8.23^{\mathrm{a}}$ \\
Organic Valley & $-28.7^{\mathrm{c}}$ & $2.53^{\mathrm{a}}$ & $3.81^{\mathrm{a}}$ \\
Store brand & $-1.75^{\mathrm{b}}$ & $4.00^{\mathrm{a}}$ & $5.29^{\mathrm{a}}$ \\
Darigold & $-25.9^{\mathrm{c}}$ & $-14.5^{\mathrm{b}}$ & $-16.3^{\mathrm{b}}$ \\
Whole milk & $20.5^{\mathrm{a}}$ & $-111.0^{\mathrm{c}}$ & $17.6^{\mathrm{b}}$ \\
$2 \%$ fat & $41.4^{\mathrm{a}}$ & $15.5^{\mathrm{b}}$ & $33.3^{\mathrm{a}}$ \\
1\% fat & $-17.3^{\mathrm{b}}$ & $50.6^{\mathrm{a}}$ & $0.36^{\mathrm{c}}$ \\
Fat free & $-44.6^{\mathrm{c}}$ & $45.0^{\mathrm{a}}$ & $-51.3^{\mathrm{d}}$ \\
Regular sugar level & $-3.40^{\mathrm{b}}$ & $-21.1^{\mathrm{b}}$ & $73.8^{\mathrm{a}}$ \\
Reduced sugar & $25.9^{\mathrm{a}}$ & $32.5^{\mathrm{a}}$ & $22.0^{\mathrm{b}}$ \\
Sugar free & $-22.5^{\mathrm{b}}$ & $-11.4^{\mathrm{b}}$ & $-95.8^{\mathrm{c}}$ \\
Organic & $-16.4^{\mathrm{b}}$ & $6.24^{\mathrm{a}}$ & $2.37^{\mathrm{a}}$ \\
Conventional & $16.4^{\mathrm{a}}$ & $-6.24^{\mathrm{b}}$ & $-2.37^{\mathrm{b}}$ \\
\hline
\end{tabular}

${ }^{\mathrm{a}-\mathrm{d}}$ Different letters within a column within an attribute are different $(P<0.05)$.

and $48 \%$ of respondents reported their eating habits were not healthy. When comparing organic milk to conventional milk, organic chocolate milk received higher utility values than conventionally made chocolate milk for cluster 3 participants. Overall, sugar reduction was not a driver for cluster 3 participants; rather, regular sugar level was a strong driver of choice in cluster 3 members.
In summary, fat was the most important driver of choice for cluster $1(\mathrm{n}=47)$ and cluster $2(\mathrm{n}=110)$ members. The difference between cluster 1 and cluster 2 consumers was brand perception. Cluster 1 members perceived brand as equally important as sugar content, whereas cluster 2 members chose sugar as more important attribute than brand name for chocolate milk. Sugar was a driver of choice in cluster $3(\mathrm{n}=$

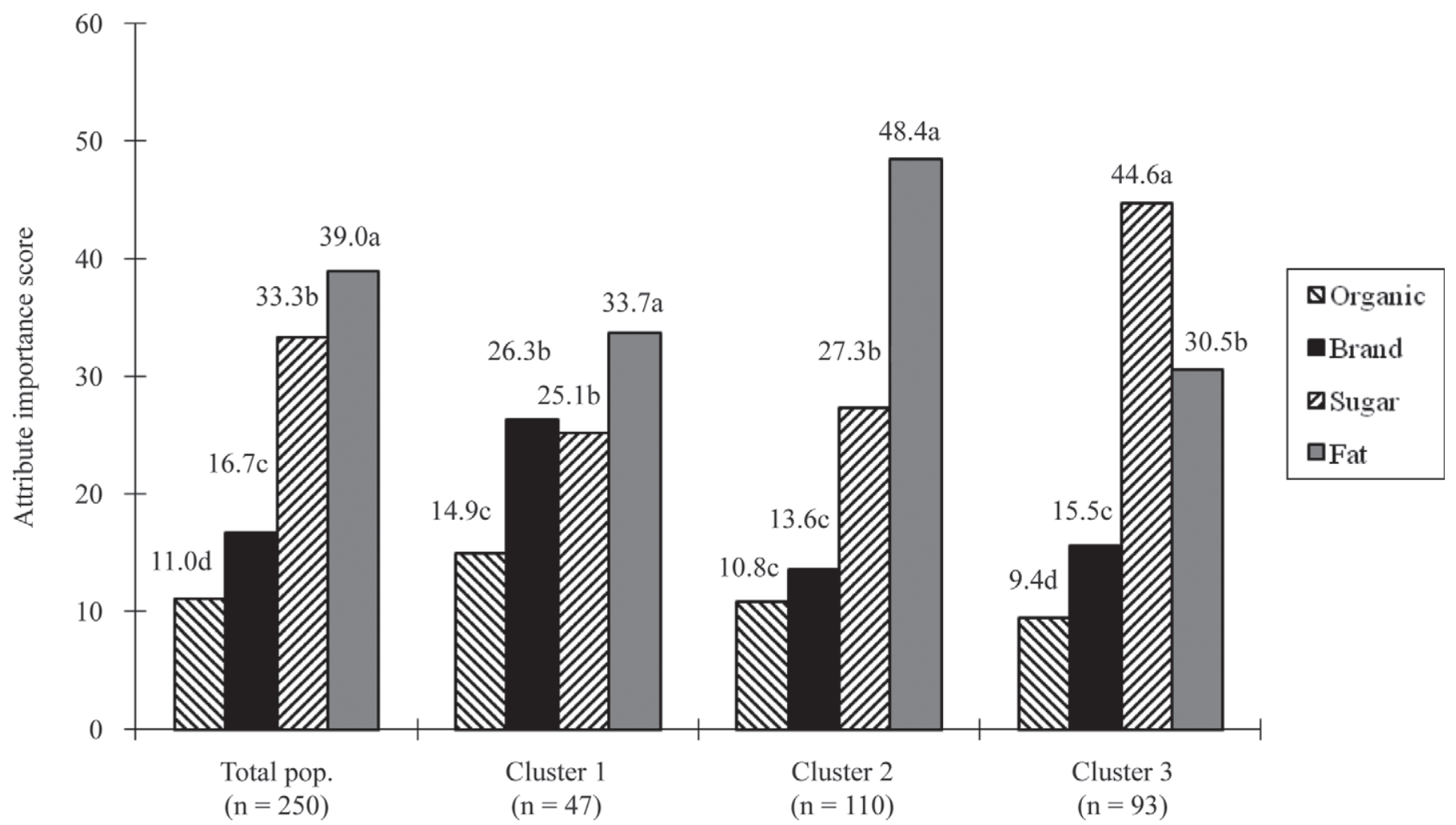

Figure 3. Attribute importance (\%) scores for the total population and segmented groups. Numbers on top of the bars represent the attribute importance $(\%)$ scores. Letters $(\mathrm{a}-\mathrm{d})$ indicate significant differences $(P<0.05)$ within each attribute for the total population $(\mathrm{n}=250)$, cluster $1(\mathrm{n}=47)$, cluster $2(\mathrm{n}=110)$, and cluster $3(\mathrm{n}=93)$. 
Table 6. Kano classifications ${ }^{1}$ of attributes and levels set for conjoint analysis of chocolate milk

\begin{tabular}{|c|c|c|c|c|}
\hline \multirow[b]{2}{*}{ Item } & \multicolumn{4}{|c|}{ Kano classification } \\
\hline & $\begin{array}{l}\text { Total } \\
(\mathrm{n}=250)\end{array}$ & $\begin{array}{l}\text { Cluster } 1 \\
(\mathrm{n}=46)\end{array}$ & $\begin{array}{l}\text { Cluster } 2 \\
(\mathrm{n}=111)\end{array}$ & $\begin{array}{l}\text { Cluster } 3 \\
(\mathrm{n}=93)\end{array}$ \\
\hline Nesquik & Indifferent & Indifferent & Indifferent & Attractor \\
\hline Organic Valley & Indifferent & Indifferent & Indifferent & Indifferent \\
\hline PET & Indifferent & Attractor & Indifferent & Indifferent \\
\hline Store brand & Indifferent & Indifferent & Indifferent & Indifferent \\
\hline Darigold & Indifferent & Indifferent & Indifferent & Indifferent \\
\hline Organic ingredient & Indifferent & Attractor & Attractor & Indifferent \\
\hline Conventional ingredient & Attractor & Attractor & Indifferent & Indifferent \\
\hline Whole milk & Attractor & Attractor & Indifferent & Attractor \\
\hline $2 \%$ fat & Attractor & Attractor & Attractor & Attractor \\
\hline $1 \%$ fat & Attractor & Attractor & Indifferent & Attractor \\
\hline Fat free & Indifferent & Indifferent & Attractor & Indifferent \\
\hline Regular sugar & Indifferent & Attractor & Attractor & Attractor \\
\hline Reduced sugar & Indifferent & Attractor & Attractor & Indifferent \\
\hline Sugar free & Indifferent & Indifferent & Indifferent & Indifferent \\
\hline
\end{tabular}

93) members. Organic label received the lowest importance scores from all 3 clusters, suggesting that organic chocolate milk is not an important driver of choice in chocolate milk.

\section{Kano Analysis}

Conjoint analysis helped to determine the drivers of choice of a product, and Kano analysis of the conjoint attributes helped to confirm and understand the drivers of consumer satisfaction of a product. Kano analysis is another tool to understand consumer satisfaction or dissatisfaction with a product (Xu et al., 2009; Kim et al., 2012). Must-have attributes are attributes that lead to extreme consumer dissatisfaction if absent, but their presence does not necessarily increase satisfaction. One-dimensional attributes are those that show linear increments of customer satisfaction with the fulfillment of those attributes. Attractor attributes are unexpected attributes that can lead to greater satisfaction if present. Indifferent attributes are those that do not affect consumer expectations of the product. Among the attributes in the Kano model, 1-dimensional attributes are the most important because these attributes are considered to be the drivers of consumer satisfaction. This study investigated the effect of each attribute and level of attribute on consumer satisfaction, specifically to determine (1) the information that played a role in customer satisfaction or dissatisfaction, and (2) whether the findings from the Kano analysis agreed with the findings from the conjoint analysis.

As identified in the conjoint analysis, fat contentrelated attributes, such as whole fat, $2 \%$ fat, and $1 \%$ fat, were identified as attractant attributes, whereas the other attributes were indifferent, except for conventional ingredients, among the total population (n $=250$ ). Attractor attributes are items that provide satisfaction if they are fully achieved; however, they do not cause dissatisfaction if they are not fulfilled (Kano et al., 1984; Xu et al., 2009). Attractor attributes were also known as exciters, as they surprise consumers unexpectedly. Interestingly, the conjoint analysis results showed that fat content was one of the drivers of choice in chocolate milk; however, the Kano analysis results suggested that fat content was an unexpected attribute that contributed to consumer satisfaction (attractor). It is important to note that other attributes were considered to be indifferent attributes, which had 2 possible interpretations: (1) these other attributes do not truly contribute to either consumer satisfaction or dissatisfaction with regard to choice of chocolate milk, or (2) segmentations were present among the consumers.

The results from the conjoint analysis and Kano analysis were compared cluster-by-cluster. In cluster 1 , the conjoint analysis results indicated that cluster 1 respondents considered fat content to be the most important attribute, followed by sugar and brand name. In terms of the fat content, whole chocolate milk and $2 \%$ fat chocolate milk received the highest utility values, and reduced sugar received the highest utility value as a sugar content attribute from conjoint analysis. A similar trend was found in the Kano analysis in that whole milk, 2 , and $1 \%$ fat content were classified as attractors, whereas the fat-free option was an indifferent attribute for cluster 1 participants (Table 6 ). In terms of the sugar attribute, cluster 1 participants gave the 
reduced sugar option a high utility score (Table 5) from conjoint analysis and the Kano analysis revealed that reduced sugar was classified as an attractor for cluster 1 participants. Among the different brands, the regional brand was an attractor for cluster 1 participants. Fat content, and to a lesser extent, sugar and brand name, were identified as drivers of choice for chocolate milk from the conjoint analysis of cluster 1 . Cluster 2 members from conjoint analysis indicated that fat content was the most important attribute, followed by sugar content. The Kano analysis showed that $2 \%$ fat and fatfree chocolate milk were attractors for these consumers, whereas whole milk and $1 \%$ milk were indifferent. It is important to note that $41 \%$ of cluster 2 participants (n $=110$ ) chose $2 \%$ chocolate milk, and $20 \%$ chose fat-free chocolate milk as their primary choice, and fat-free or $1 \%$ fat chocolate milk received high utility scores in fat attribute from conjoint analysis. These Kano analysis results were in line with the conjoint analysis results and consumer consumption characteristics. Therefore, many attributes that were identified as indifferent attributes when the total consumers surveyed were analyzed were, in fact, influential attributes within specific consumer clusters. Similar to the findings for cluster 1 , reduced sugar and nonreduced sugar options were attractor qualities for cluster 2 participants, whereas sugar-free was classified as an indifferent attribute, which means it did not make a difference to consumer satisfaction. The reduced sugar option received high utility scores from conjoint analysis. Unlike cluster 1, brand received the lowest utility score from conjoint analysis from cluster 2 consumers, and Kano analysis also showed that all 5 brands were classified as indifferent attributes for cluster 2 . It is worth noting that organic ingredients were classified as attractors for cluster 2 and cluster 1 consumers. However, an organic label was not an important driver of choice for chocolate milk from conjoint analysis, therefore the result from conjoint analysis and Kano analysis on organic ingredients for clusters 1 and 2 consumers were not in agreement. Again, the objective of Kano analysis is to find the driver of consumer satisfaction of a product, whereas conjoint analysis is performed to determine the driver of choice. Based on these results, it can be concluded that an organic label is important to increase satisfaction of chocolate milk; however, it does not drive the choice of chocolate milk.

Cluster 3 consumers from conjoint analysis were different than the cluster 1 and 2 consumers: sugar content was the driver for cluster 3 participants. The Kano analysis revealed that regular sugar (i.e., the nonreduced option) was an attractor attribute among the sugar content attributes, which indicated that the nonreduced sugar option (regular sugar level) could contribute to consumer satisfaction of chocolate milk. This result is in agreement with the conjoint analysis results in which regular sugar levels received the highest utility value for sugar content attributes from cluster 3 consumers. The Kano analysis showed that whole fat, 2 , and $1 \%$ fat content also were classified as attractor attributes, whereas fat-free was an indifferent attribute in terms of consumer satisfaction of chocolate milk for cluster 3 participants. From conjoint analysis, $2 \%$ fat level received the highest utility score of fat attributes from cluster 3 consumers. Kano analysis and conjoint analysis results were generally in agreement. Studying consumers using different methods from different perspectives (e.g., conjoint analysis and Kano analysis) allowed a confirmation of which of the attributes were important for consumer choice of chocolate milk.

\section{CONCLUSIONS}

This study investigated the effects of packaging and brand name on consumer choices of chocolate milk. A limited number of samples and packaging variables were evaluated, which is a limitation of this study. However, results from our 3 experimental approaches (consumer acceptance, conjoint survey, Kano questionnaire) confirmed that consumer acceptance of chocolate milk was influenced by the presence of brand and declared fat content information. Among the information shown on the package of chocolate milk, fat content was the driver of choice for purchasing chocolate milk, followed by sugar content and brand. Consistent with previous studies on other foods, a fat-free label was not appealing to many consumers. Instead, 1 or $2 \%$ milk was preferred for purchase even though consumers preferred the flavor of whole milk chocolate milk after actual tasting. Organic labeling did not affect the purchase decision of chocolate milk; however, Kano results revealed that having an organic label on a package had a positive influence on consumer satisfaction of chocolate milk. Overall, intrinsic cues (sensory attributes including fat and sugar), rather than extrinsic cues (brand name, packaging labels) drive the choice for chocolate milk, especially when consumers can actually taste the milk. Findings from this study can help chocolate milk producers as well as food marketers better target their product labels with attributes that drive consumer choice of chocolate milk.

\section{ACKNOWLEDGMENTS}

Funding was provided in part by the Dairy Research Institute (Rosemont, IL). The use of trade names does not imply endorsement or lack of endorsement by those not mentioned. 


\section{REFERENCES}

Anonymous. 2003. Tools for innovation: Dairy foods for today's preteens. Accessed Feb. 2012. http://www.dairyfoods.com/articles/ tools-for-innovation-dairy-foods-for-today-s-pre-teens.

Arcia, P. L., A. Curutchet, E. Costell, and A. Tarrega. 2012. Influence of expectations created by label on consumers' acceptance of Uruguyan low fat cheeses. J. Sens. Stud. 27:344-351.

Bayarri, S., I. Carbonell, E. X. Barrios, and E. Costell. 2010. Acceptability of yogurt and yogurt-like products: Influence of product information and consumer characteristics and preferences. J. Sens. Stud. 25:171-189.

Berger, C., B. Robert, D. Boger, C. Bolster, G. Burchil, W. DuBouchel, F. Pouliot, R. Richter, A. Rubinoff, D. Shen, M. Timko, and D. Walden. 1993. Kano's methods for understanding customer defined quality. Cent. Qual. Manag. J. 4:3-36.

Bermudez-Aguirre, D., J. A. Yanez, C. P. Dunne, N. M. Davies, and G. V. Barbosa-Canovas. 2010. Study of strawberry flavored milk under pulsed electric field processing. Food Res. Int. 43:2201-2207.

Bower, J. A., and L. Turner. 2001. Effect of liking, brand name and price on purchase intention for branded, own label and economy line crisp snack foods. J. Sens. Stud. 16:95-115.

Brewer, J. L., A. J. Blake, S. A. Rankin, and L. W. Douglas. 1999. Theory of reasoned action predicts milk consumption in women. J. Am. Diet. Assoc. 99:39-44.

Cardello, A. V. 2007. Measuring consumer expectations to improve food product development. Pages 223-252 in Consumer-Led Food Product Development. H. Macfie, ed. Woodhead Publishing Ltd., Cambridge, UK.

CDC (Centers for Disease Control and Prevention). 2010. Effects of switching from whole to low-fat/fat-free milk in public schools. Morb. Mortal. Wkly. Rep. 59:70-73.

Childs, J. L., and M. A. Drake. 2009. Consumer perception of fat reduction in cheese. J. Sens. Stud. 24:902-921.

Cleophas, T. J., and A. H. Zwinderman. 2002. Crossover studies with continuous variables: Power analysis. Am. J. Ther. 9:69-73.

CMN (Cheese Market News). 2012. Industry continues to push for more school milk options. Cheese Market News 31:1-12.

Cunningham, C. E., K. Deal, and Y. Chen. 2010. Adaptive choicebased conjoint analysis: A new patient-centered approach to the assessment of health service preferences. Patient 3:257-273.

Garey, J. G., M. M. Chan, and S. R. Parlia. 1990. Effect of fat content and chocolate flavoring of milk on meal consumption and acceptability by schoolchildren. J. Am. Diet. Assoc. 90:719-721.

Golub, M., M. Charlop, E. A. Groisman-Perelstein, R. Charmaine and N. Calman. 2011. Got low fat milk? How a community-based coalition changed school milk policy in New York City. Fam. Community Health 34:S44-S53.

Guerrero, L. 1995. Does the consumer read and understand the product information? Product information and acceptability. AirCat Workshop. Nov. 17-18. Helsinki, Finland.

Guerrero, L., Y. Colomer, M. D. Guardia, J. Xicola, and R. Clotet. 2000. Consumer attitude towards store brands. Food Qual. Prefer. 11:387-395.

Guinard, J.-X., B. Uotani, and P. Schilich. 2001. Internal and external mapping of preferences for commercial lager beers: Comparison of hedonic ratings by consumers blind versus with knowledge of brand and price. Food Qual. Prefer. 12:243-255.

Hoag, C. 2011. Flavored milk banned in LA schools. Accessed Apr. 2012. http://www.huffingtonpost.com/2011/06/15/la-schoolsflavored-milk_n_877282.html?view=print\&comm_ref=false.

Hoyer, W. D., and S. P. Brown. 1990. Effects of brand awareness on choice for a common, repeat-purchase product. J. Consumer Res. $17: 141-148$.
International Dairy Foods Association. 2010. Dairy Facts. 2010 Edition. Accessed Jan. 2012. http://www.jimogden.com/files/D.P._ Information.pdf.

Jaeger, S. R. 2006. Non-sensory factors in sensory science research. Food Qual. Prefer. 17:132-144.

Jervis, S. M., K. Lopetcharat, and M. A. Drake. 2012a. Application of ethnography and conjoint analysis to determine key consumer attributes for latte style coffee beverages. J. Sens. Stud. 27:48-58.

Jervis, S. M., J. Ennis, and M. A. Drake. 2012b. A comparison of choice based conjoint versus adaptive choice based conjoint in the evaluation of drivers of choice of sour cream. J. Sens. Stud. $27: 451-462$.

Johnson, R. K., C. Frary, and M. Q. Wang. 2002. The nutritional consequences of flavored-milk consumption by school-aged children and adolescents in the United States. J. Am. Diet. Assoc. 102:853-856.

Kano, N., N. Seraku, F. Takahashi, and T. Tsujis. 1984. Attractive quality and must-be quality. J. Jpn. Soc. Qual. Control 2:39-48.

Kiesel, K., and S. B. Villas-Boas. 2007. Got organic milk? Consumer valuations of milk labels after the implementation of the USDA organic seal. J. Agric. Food. Ind. Organ. 5:1-40.

Kim, M. K., K. Lopetcharat, P. D. Gerard, and M. A. Drake. 2012. Consumer awareness of salt and sodium and sodium reduction labeling. J. Food Sci. 77:S307-S313.

Murphy, M. M., J. S. Douglass, R. K. Johnson, and L. A. Spence 2008. Drinking flavored or plain milk is positively associated with nutrient intake and is not associated with adverse effects on weight status in US children and adolescents. J. Am. Diet. Assoc. 108:631-639.

Olsen, N. V., E. Menichelli, C. Meyer, and T. Naes. 2011. Consumers liking of private labels. A evaluation of intrinsic and extrinsic orange juice cues. Appetite 56:770-777.

Orme, B. K. 2006. Getting Started With Conjoint Analysis: Strategies for Product Design and Pricing Research. 3rd ed. Research Publishers LLC, Madison, WI.

Richardson, P. S., A. S. Dick, and A. K. Jain. 1994. Extrinsic and intrinsic cue effects on perceptions of store brand quality. J. Mark. $58: 28-36$.

Schantz, R. M., and J. S. Pontius. 1994. Graphical applications in the analysis of crossover designs in food sensory studies. J. Sens. Stud. 9:57-67.

Shepherd, R., M. Magnusson, and P.-O. Sjoden. 2005. Determinants of consumer behavior related to organic foods. Ambio. 34:352-359.

Spaccarotella, K. J., and W. Andzel. 2011. Building a beverage for recovery from endurance activity: A review. J. Strength Cond Res. 25:3198-3204.

Thompson, J. L., M. A. Drake, K. Lopetcharat, and M. D. Yates. 2004. Preference mapping of commercial chocolate milks. J. Food Sci. 69:406-413.

Thompson, J. L., P. D. Gerard, and M. A. Drake. 2007. Chocolate milk and the Hispanic consumer. J. Food Sci. 72:S666-S675.

Torres-Moreno, M., A. Tarrega, E. Torrescasana, and C. Blanch. 2012. Influence of label information on dark chocolate acceptability. Appetite 58:665-671.

Varela, P., G. Ares, A. Gimenez, and A. Gambaro. 2010. Influence of brand information on consumers' expectations and liking of powdered drinks in central location tests. Food Qual. Prefer. $21: 873-880$.

Xu, Q., R. J. Jiao, X. Yang, and M. Helander. 2009. An analytical Kano model for customer need analysis. Des. Stud. 30:87-110.

Yon, B. A., R. K. Johnson, and T. R. Stickle. 2012. School children's consumption of lower-calorie flavored milk: A plate waste study. J. Acad. Nutr. Diet 112:132-136. 